\title{
Characterizing Autonomy Supportiveness in Diabetes Peer Health Coaches
}

\author{
Jacob Cedarbaum*, MD; Brianne Brown ${ }^{\dagger}, \mathrm{MPH}$; Shayla Wilson ${ }^{\ddagger}, \mathrm{MPH}$; \\ Rebecca Mase ${ }^{\S}$, MSW; Mary Ellen Michele Heisler ${ }^{\llbracket}, \mathrm{MD}, \mathrm{MPH}$
}

\section{Background}

Prior studies have shown that peer health coaching improves outcomes among adults with chronic conditions such as diabetes. These studies have also suggested that higher ratings of their peer coach's autonomy supportiveness, ie, the degree to which a coach supports participant choice, is associated with improved outcomes. The types of actual behaviors and interactions that participants in these coaching relationships perceive as being more or less autonomy supportive are important to define. This investigation aims to more concretely characterize the ways in which participants perceive autonomy support and how important these perceptions are to their satisfaction with their peer coaches.

\section{Methods}

This article is a qualitative investigation of the US Department of Veterans AffairsTechnology Enhanced Coaching (VA-TEC) study, a parallel randomized controlled trial with diabetes patients with poor glycemic control at the Detroit VA Medical Center. Intervention arm participants work for 6 months with peer coaches who are also VA patients who now have good glycemic control. Researchers conducted semistructured interviews with veterans who had recently completed their 6 months of coaching. Responses to Health Care Climate Questionnaire (HCCQ) items in the trial's 6-month survey were used to identify veterans for interviews who rated their coaches either especially high or low in terms of autonomy supportiveness. Interview responses were then analyzed in order to elucidate veterans' perceptions of autonomy support in their coaching relationships.

"University of Michigan, jcedarb@med.umich.edu

tUniversity of Michigan, brimich@med.umich.edu

抽iversity of Michigan, swil@med.umich.edu

§University of Michigan, rmase@med.unmich.edu

"University of Michigan, mheisler@med.umich.edu

doi: $10.3998 / \mathrm{mjm} .1432$

Conflicts of interest:

The authors have no conflicts of interest to disclose 


\title{
Results
}

Semi-structured interviews were conducted with 17 of the veterans who completed the VA-TEC program. Veterans who rated their coaches higher on HCCQ items tended to emphasize the positivity and non-judgmental nature of their coaches. They also described coaches who offered them choices and non-directive suggestions in identifying health behavior goals. Veterans who gave their coaches lower HCCQ ratings described coaches who tended to be less personally engaged and less focused on addressing veterans'specific concerns about diabetes. Some veterans who rated their coaches lower on autonomysupportiveness felt their coaches underestimated their existing knowledge of diabetes and were overly directive in providing advice. Overall, participants' HCCQ ratings correlated well with expressed satisfaction with their coach in interviews.

\section{Conclusions}

VA-TEC participant feedback outlines meaningful ways in which coaches can support autonomy. These include, among others, eliciting participants' personal goals, remaining positive and non-judgmental, providing suggestions for behavior changes without being overly directive, and maintaining a balance between discussing diabetes and the types of personal conversations that are crucial to building trust. The effective behaviors described in this investigation can be used to train future coaches and other lay health workers.

\author{
Keywords \\ diabetes $\bullet$ peer $\bullet$ support
}

\section{Introduction}

The United States and other high-income countries have seen a dramatic rise in the number of patients needing long-term support for chronic medical conditions, including type 2 diabetes. In the US Department of Veterans Affairs (VA) health system, the backdrop for this study, approximately $20 \%$ of patients have diabetes. Within that group, $15 \%$ to $30 \%$ are reported as having persistently poor control of their disease, as indicated by A1c levels greater than or equal to $9.0 \% .^{1}$ Many patients face substantial barriers to effective diabetes self-management, such as difficulties with medication adherence, frequent blood sugar monitoring, and challenging lifestyle modifications, in addition to the significant financial and time burdens that these entail. Such barriers are especially prevalent for low-income, ethnic minority populations who represent a large proportion of VA patients. Beyond having fewer resources, these individuals often report high levels of diabetes-specific distress, lower engagement in clinic visits, and poor health literacy —all of which are associated with worse health outcomes. ${ }^{2-8}$

In light of these barriers, peer support among patients with diabetes shows promise as an effective and cost-effective intervention. "Peer support" is defined as "support from a person who has experiential knowledge of a specific behavior or stressor and similar characteristics as the target population." ${ }^{9}$ Peer support and coaching help reduce problematic health behaviors and, in both VA and non-VA randomized controlled trials, have contributed to improved diabetes management. ${ }^{9-17}$

Several studies have demonstrated that higher ratings of peer health coaches' autonomy supportiveness (AS), ie, the degree to which a coach supports participant choice, is associated with improved outcomes. ${ }^{10,18}$ Little is known, however, about which specific coach behaviors and characteristics are perceived by patients as being more or less autonomy 
supportive. This investigation aims to address this question by more concretely characterizing the ways in which participants perceive AS in the context of a diabetes peer health coaching relationship.

\section{Methods}

The VA-Technology Enhanced Coaching (VA-TEC) study is a parallel, randomized controlled trial that involved 290 patients with diabetes who had poor glycemic control (defined for this study as having an A1c greater than 8.0\%). Patients were recruited from the John D. Dingell VA Medical Center in Detroit, Michigan. Veteran participants were randomized to one of two intervention arms: (1) technology-enhanced coaching (TEC) using a customizable online tool or (2) peer coaching, alone. Veterans in both groups worked for 6 months with peer health coaches who also had diabetes and were also VA patients.

Coaches were internally recruited based on having achieved good glycemic control (defined as an A1c of less than 7.5\%) after formerly having poor glycemic control. Prior to being matched with veteran participants, all coaches received 2 to 3 hours of training in autonomy-supportive coaching techniques, including motivational interviewing. Coaching dyads in both intervention arms initially met face-to-face to review educational materials and develop action plans. Over the subsequent 6-month period, coaches and veterans communicated primarily by phone on at least a weekly basis to work on targeted action steps. Both peer coaches and the veteran participants completed written surveys and underwent measurement of A1c and blood pressure upon entry into the trial, as well as at 6 months and 12 months. ${ }^{17}$

This article focuses on a discussion of semi-structured interviews that were conducted with a purposeful sample of veterans who had recently completed their 6 months of being coached. Responses to items on the Health Care Climate Questionnaire (HCCQ), a validated measure of autonomy supportiveness, were built into the 6-month survey to identify for interviews veterans who rated their coaches either especially high or low in terms of autonomy supportiveness. High-HCCQ rating participants were determined as those who selected ratings of 6 or 7 on the HCCQ's 7-point scale for a majority of items. Conversely, low HCCQ rating participants gave ratings of 3 or lower for most items.

Qualitative data from 17 interviews with high and low autonomy supportive coaches were reviewed and coded for specific themes in order to elucidate veterans' characterization and perceptions of autonomy support in their coaching relationships.

\section{Results}

Veterans who perceived their coaches as being more autonomy supportive, based on higher HCCQ ratings, tended to emphasize the positivity and non-judgmental nature of their coaches. Several such veterans appreciated how their coaches would not chastise or shame them for their blood glucose levels or falling short on diet or exercise goals, in comparison to the criticism they perceived from medical professionals. One veteran noted that "the feedback was mostly positive, so it wasn't anything like, darn, I don't want to have to talk to this guy." Positive, non-judgmental coaches were not only able to foster more open, trusting peer relationships, but they also made participants want to stay engaged with the program.

High HCCQ-rating veterans also described coaches who elicited participants' goals, offered them choices, and emphasized non-directive collaboration in identifying health behavior goals and forming action plans. "I would let him know what I wanted to do and then he would make 
Table 1. Traits of Coaches With High Ratings of Autonomy Support

\begin{tabular}{|l|l|}
\hline Traits & \multicolumn{1}{|c|}{ Representative quote } \\
\hline Empathetic listening & $\begin{array}{l}\text { "He was willing to listen as much as he talked, and that was } \\
\text { very helpful. You have to be willing to hear what other people } \\
\text { say instead of just throwing your opinions at them." }\end{array}$ \\
\hline Positive framing & $\begin{array}{l}\text { "My coach regularly encouraged me on eating healthy and } \\
\text { staying active and he didn't chastise me if I slipped. I could } \\
\text { really tell he cared." }\end{array}$ \\
\hline $\begin{array}{l}\text { Non-directive } \\
\text { collaboration }\end{array}$ & $\begin{array}{l}\text { "Goal setting was a collaborative thing. . . He never said you } \\
\text { need to do this or you need to change that. . . He would make } \\
\text { suggestions." }\end{array}$ \\
\hline Non-judgmental approach & $\begin{array}{l}\text { "He's not judgmental. . . People my age do not like being told } \\
\text { what to do. And when someone asks you about what you're } \\
\text { doing in a comfortable way, it's harder to argue with that." }\end{array}$ \\
\hline $\begin{array}{l}\text { Modeling healthy } \\
\text { behaviors }\end{array}$ & $\begin{array}{l}\text { "He wouldn't just tell me to go out and do something; he } \\
\text { would tell me what he was going to do and kind of inspire me } \\
\text { to do something." }\end{array}$ \\
\hline
\end{tabular}

suggestions and give input from there," reported one veteran. A number of other participants specifically commented on the importance of coaches focusing on goals important to them rather than being overly prescriptive. "I expected it to be more like a football coach, encouraging you and egging you on all the time, but actually, it was a perfect relationship. He didn't push too hard, [in which case] I would have withdrew [sic] more," noted a participant.

Yet another important component to the perception of autonomy supportiveness was the notion that participants' peer coaches were modeling similar disease management behaviors in their own lives. One veteran reflected that "you can tell the difference talking to someone like a doctor versus talking to someone going through the same thing as you." Coaches served as tangible, accessible models for the disease management success that participants could attain through adopting similar lifestyle changes. Another interviewee commented, "With the health provider they hear you but they don't hear you. . . It's more personal [with a peer coach] since you're going through the same stuff and you can say 'You went through that? How did you deal with that?" In fact, all high HCCQ-rating participants interviewed described being inspired by their coaches having struggled with poor glycemic control.

Veterans who gave their coaches lower HCCQ ratings described coaches who tended to be less personally engaged and less focused on addressing veterans' specific concerns about diabetes. Several of those interviewed described coaches who rushed interactions and gave the sense that their weekly interactions were more about completing a required task than about developing a genuine relationship. "[My coach] often seemed eager to be done with the conversation. He made his phone call, we talked, we saw each other was doing okay and then would do it again next Tuesday." Another veteran reflected that his coach "just didn't seem to care. It would have been nice to have a coach ask me questions." This reflects another widely expressed critique of low AS coaches being perceived as not personally invested in or caring about their veterans. 
Table 2. Traits of Coaches With Low Ratings of Autonomy Support

\begin{tabular}{|l|l|}
\hline Traits & \multicolumn{1}{|c|}{ Representative quote } \\
\hline Low personal engagement & $\begin{array}{l}\text { "He always seemed to be in a hurry to go do whatever else he } \\
\text { needed to do. . . He didn't seem to be interested so I didn't } \\
\text { bother to ask [about suggestions and support for diabetes } \\
\text { management]." }\end{array}$ \\
\hline $\begin{array}{l}\text { Undervaluing participant } \\
\text { knowledge }\end{array}$ & $\begin{array}{l}\text { "I think I knew more about diabetes than he did. And just like } \\
\text { with a teacher, if you feel like you know more than they do } \\
\text { then you just tune them out. .. It was no new information, } \\
\text { just 'how are you feeling today?" }\end{array}$ \\
\hline Lack of focus on diabetes & $\begin{array}{l}\text { "I expected more specifics on diabetes care or what to look } \\
\text { out for and it was just more general discussion- like having a } \\
\text { friend call." }\end{array}$ \\
\hline Poor goal setting & $\begin{array}{l}\text { "We did [set a goal] but it wasn't important enough for me to } \\
\text { remember. . . There was no real concrete plan to achieve the } \\
\text { goal." }\end{array}$ \\
\hline Overly directive approach & $\begin{array}{l}\text { "When we talked he used to tell me 'you need to do this.' He } \\
\text { wasn't telling me things I didn't already know." }\end{array}$ \\
\hline
\end{tabular}

Other veterans were discouraged by conversations that they felt did not focus on their goals for management. One such veteran remarked, "Was [the coach] here to be a diabetic coach and set goals for a program or was it just a social call?" Another commented that "[my coach] told me his experience with diabetes but he wasn't very specific with what he did. It was like having a friend call and I'd talk for a while but diabetes didn't seem to be the main focus."

In contrast to feedback from high HCCQ-rating participants, many veterans who perceived low levels of AS in their coaches did not see their coaches as good role models for healthy behaviors or as knowledgeable about diabetes. Some described their coaches as seeming lazy or were put off by the sense that their own disease management was better than that of their coaches. One veteran questioned, "I was just wondering if [my coach] was actually doing this himself. How can you project something if you're not doing it yourself?"

\section{Conclusion}

Themes elicited from the qualitative responses of VA-TEC participants help to characterize the types of behaviors that peers perceived as being more or less autonomy supportive. In general, behaviors perceived as being more autonomy supportive included eliciting participants' personal goals, remaining positive and non-judgmental in interactions, providing suggestions for behavior changes without being overly directive, and maintaining a balance between discussions of diabetes management and the types of personal conversations that are crucial to building trust. Conversely, behaviors associated with lower perceptions of autonomy supportiveness included seeming personally disengaged, undervaluing participants' existing knowledge, and failing to elicit participants' goals or being overly directive in goal setting and action planning. The positive autonomy supportive behaviors described in this investigation 
can be used to train future peer coaches, other lay health workers, and even medical professionals to be more effective in helping their patients to take ownership of and successfully manage chronic disease.

\section{Acknowledgments}

University of Michigan Medical School Summer Biomedical Research Program.

\section{References}

1. Veterans Health Administration. VHA Office of Quality and Performance Report. US Dept of Veterans Affairs; 2011. http://vaww.pdw.med.va.gov/MeasureMaster/MMReport.asp

2. Gallant MP. The influence of social support on chronic illness self-management: a review and directions for research. Health Educ Behav. 2003;30(2):170-195. doi:10.1177/1090198102251030

3. Goldman ML, Ghorob A, Hessler D, Yamamoto R, Thom DH, Bodenheimer T. Are low-income peer health coaches able to master and utilize evidence-based health coaching? Ann Fam Med. 2015;13(suppl 1):S36-S41. doi:10.1370/afm.1756

4. Spencer MS, Kieffer EC, Sinco BR, et al. Diabetes-specific emotional distress among African Americans and Hispanics with type 2 diabetes. J Health Care Poor Underserved. 2006;17(2 suppl): 88-106. doi:10.1353/hpu.2006.0095

5. Osborn CY, Cavanaugh K, Wallston KA, White RO, Rothman RL. Diabetes numeracy: an overlooked factor in understanding racial disparities in glycemic control. Diabetes Care. 2009;32(9):1614-1619. doi:10.2337/dc09-0425

6. Schillinger D, Barton LR, Karter AJ, Wang F, Adler N. Does literacy mediate the relationship between education and health outcomes? A study of a low-income population with diabetes. Public Health Rep. 2006;121(3):245-254. doi:10.1177/003335490612100305

7. Heisler M, Bouknight RR, Hayward RA, Smith DM, Kerr EA. The relative importance of physician communication, participatory decision making, and patient understanding in diabetes self-management. J Gen Intern Med. 2002;17(4):243-252. doi:10.1046/j.1525-1497.2002.10905.x

8. Piette JD, Schillinger D, Potter MB, Heisler M. Dimensions of patient-provider communication and diabetes self-care in an ethnically diverse population.J Gen Intern Med.2003;18(8):624-633. doi:10.1046/j.1525-1497.2003.31968.x

9. Ghorob A, Vivas MM, De Vore D, et al. The effectiveness of peer health coaching in improving glycemic control among low-income patients with diabetes: protocol for a randomized controlled trial. BMC Public Health. 2011;11:208. doi:10.1186/1471-2458-11-208

10. Leahey TM, Wing RR. A randomized controlled pilot study testing three types of health coaches for obesity treatment: professional, peer, and mentor. Obesity (Silver Spring). 2013;21(5):928-934. doi:10.1002/oby.20271

11. Heisler M, Vijan S, Makki F, Piette JD. Diabetes control with reciprocal peer support versus nurse care management: a randomized trial. Ann Intern Med. 2010;153(8):507-515. doi:10.7326/0003-4819-153-8-201010190-00007

12. Rogers EA, Hessler DM, Bodenheimer TS, Ghorob A, Vittinghoff E, Thom DH. Diabetes peer coaching: do "better patients" make better coaches? Diabetes Educ. 2014;40(1):107-115. doi:10.1177/0145721713513178

13. Strecher VJ, McClure JB, Alexander GL, et al. Web-based smoking-cessation programs: results of a randomized trial. Am J Prev Med.2008;34(5):373-381. doi:10.1016/j.amepre.2007.12.024

14. Thom D, et al. Peer health coaching improves glycemic in low-income patients with diabetes: a randomized controlled trial. Forthcoming. 
15. Harada ND, Damron-Rodriguez J, Villa VM, et al. Veteran identity and race/ethnicity: influences on VA outpatient care utilization. Med Care. 2002;40(1 suppl):I117-I128.

16. Heisler M, Mase R, Brown B, Wilson S, Reeves PJ. Study protocol: the Technology-Enhanced Coaching (TEC) program to improve diabetes outcomes—a randomized controlled trial. Contemp Clin Trials. 2017;55(4):24-33. doi:10.1016/j.cct.2017.01.006

17. Zhang X, Yang S, Sun K, Fisher EB, Sun X. How to achieve better effect of peer support among adults with type 2 diabetes: a meta-analysis of randomized clinical trials. Patient Educ Couns. 2016;99(2):186-197. doi:10.1016/j.pec.2015.09.006

18. Williams G, McGregor HA, King D, Nelson CC, Glasgow RE. Variation in perceived competence, glycemic control, and patient satisfaction: relationship to autonomy support from physicians. Patient Educ Couns. 2005;57(1):39-45. doi:10.1016/j.pec.2004.04.001

(C) 2021 Author(s)

This is an open-access article distributed under the terms of the Creative Commons Attribution 4.0 International license, which permits anyone to download, copy, distribute, display, or adapt the text without asking for permission, provided that the creator(s) are given full credit.

ISSN 2470-9727 